\title{
Abduction by philosophers: reorienting philosophical methodology
}

Article

Accepted Version

Andow, J. (2016) Abduction by philosophers: reorienting philosophical methodology. Metaphilosophy, 47 (3). pp. 353370. ISSN 1467-9973 doi: https://doi.org/10.1111/meta.12191 Available at https://centaur.reading.ac.uk/65758/

It is advisable to refer to the publisher's version if you intend to cite from the work. See Guidance on citing.

To link to this article DOI: http://dx.doi.org/10.1111/meta.12191

Publisher: Blackwell Publishing

All outputs in CentAUR are protected by Intellectual Property Rights law, including copyright law. Copyright and IPR is retained by the creators or other copyright holders. Terms and conditions for use of this material are defined in the End User Agreement.

\section{www.reading.ac.uk/centaur}

\section{CentAUR}

Central Archive at the University of Reading

Reading's research outputs online 


\title{
Abduction by Philosophers: Reorienting Philosophical Methodology*
}

\author{
James Andow \\ June 3, 2016
}

\begin{abstract}
A reorientation is needed in methodological debate about the role of intuitions in philosophy. Methodological debate has lost sight of the reason why it makes sense to focus on questions about intuitions when thinking about the methods or epistemology of philosophy. The problem is an approach to methodology which gives a near exclusive focus to questions about some evidential role that intuitions may or may not play in philosophers' arguments. A new approach is needed. Approaching methodological questions about the role of intuitions in philosophy with an abductive model of philosophical enquiry in mind will help ensure the debate doesn't lose sight of what motivates the debate.
\end{abstract}

Keywords: intuitions, methodology, philosophical methods, epistemology of philosophy, abduction

I have long harbored misgivings about the focus given to intuitions in recent debates about philosophical methodology. This paper is my best effort to give voice to those misgivings and to suggest how debate might be reoriented as to address them.

$\$ 1$ articulates my misgivings. In short, the concern is that debate in philosophical methodology has got sidetracked by focusing on some evidential role that intuitions may or may not play in philosophers' arguments rather than in philosophy. By saying that debate has got sidetracked, I mean that debate has ended up proceeding in such a way that it is completely disengaged from the reasons why looking at the evidential role of intuitions seemed like a promising starting place for the methodologist. It has lost sight of why it makes sense to methodologically examine the role of intuitions

*This paper is forthcoming in Metaphilosophy. Please cite final published version. Acknowledgements: Thanks to Jules Holroyd, Greg Currie and Pendaran Roberts for comments on early drafts of this material. Thanks also to an anonymous reviewer for this journal. 
in philosophy. It is worth noting from the start that there is currently somewhat of a fashion to voice misgivings about the focus which has been given to discussion of intuitions in debates about philosophical methodology. This paper is not part of that trend. Indeed my misgivings extend to that trend and the examples used in $\$ 1$ will include a number of contributions which are part of that trend about which I have misgivings.

$\$ 2$ makes a suggestion as to how methodological debate might be reoriented to address my misgivings. In short, the suggestion is to recommend an abductive model of philosophical enquiry according to which the overall project of giving a theory of some phenomenon is at heart an abductive exercise. This model allows for constructive examination of the methods of philosophy but doesn't allow us to so easily lose sight of the reasons we have for taking seriously the idea that intuitions are central to philosophical methods and epistemology. This model is also distinct from various other recent suggestions that philosophical enquiry may have a more abductive flavor than is typically recognized. A significant portion of the work of this section will thus be to distinguish the model advanced from various distinct ideas one might entertain about the relation between philosophy and abduction. One mistake, essentially the same thing I have misgivings about, would be to assume that any helpful model for understanding the role of intuitions in philosophical enquiry would have to be a model of how intuitions (do or do not) play an evidential role in philosophers' arguments.

\section{Misgivings}

For some time now, discussion about philosophical methods has tended to focus on the role of intuitions in philosophy. In fact, the focus has been rather more specific than that. The discussion has been about whether intuitions play an evidential role. And this discussion tends to be focused on philosophers' arguments and what role intuitions are playing in those arguments and in particular whether it is evidential. I have misgivings about this particular focus. But before I get to those, let me make clear that I don't think it is a mistake to focus on the role of intuitions in philosophy or even on some evidential role that intuitions may or may not play.

\subsection{Why focus on intuitions in methodology?}

I do think that it makes sense for methodologists to focus on the role of intuitions. Why? Because there is a very plausible picture of philosophy's methodology and epistemology which gives intuitions a central role. ${ }^{1}$ What is this picture? And why

\footnotetext{
${ }^{1}$ Here I distinguish between the epistemology of philosophy and the methodology. This is an important distinction. The issues of how philosophers proceed generally and how philosophers go
} 
is it plausible?

To answer those questions, let me start with the observation that the epistemology of philosophy presents a bit of a puzzle. Here's one way to look at the puzzle. Ask yourself: what could possibly provide evidential support in philosophical enquiry? In some domains, one can use one's senses to gather empirical evidence. But, when we want to know about morality, metaphysics, and art such evidence seems to be of limited importance. Instead, when we philosophize about such things we use our rational faculties; we reason counterfactually about hypothetical/imaginary cases; we place some (pro tanto) faith in our pretheoretic beliefs, our ordinary ways of thinking, in the judgments we are disposed to have about philosophically important matters when we reflect upon them, etcetera. We can't get all our evidence via the senses, memory and testimony. It seems that some of it has to come from elsewhere. But, where could it come from? Approaching from this direction, the puzzle is that it can be a little mysterious where the justification for the sorts of claims we want to make in philosophy comes from. What assurance have we that we are on the path to truth? Here's another way to look at what I take to be the same central puzzle. Ask yourself: what is going on when philosophers philosophize? We have a clear enough understanding of scientific experimental methods, and it might looks as if philosophers do some very similar things. Where scientists perform experiments to test theories, philosophers perform thought experiments. But, what plays the analogous role to observations in philosophy?

So far, we haven't really used the word 'intuition'. But both these ways of looking at the puzzle seem to be very naturally captured in terms of intuitions. Just use the word 'intuition' to label that whose status in the epistemology of philosophy generates these sorts of puzzles. Philosophers seem to use apparently non-empirical judgments about all sorts of propositions, cases and theories in building their theories. Such judgements somehow seem to feature prominently in stories about which theories philosophers accept/reject and about the support or justification philosophers provide for theories. Historical associations which the word 'intuition' facilitate an analogy between 'intuitions' and perceptual judgments and in other ways make the word a very natural one to use.

Out of all this drops a prima facie somewhat plausible picture of philosophy's methods and epistemology: philosophers use intuitions and their use of intuitions has something to do with evidence, justification, or support (where what is meant by 'intuitions' is a somewhat vague, rather imprecise notion which collects together various things like pretheoretic beliefs and judgments we are disposed to have concerning actual and hypothetical cases, and other stuff too). We might call this picture

about providing justification for their views versus the issue of what justifies philosophical positions are distinct matters. However, the two are closely linked and often not clearly distinguished in the literature. In this paper, I urge a reorientation of all metaphilosophical discussions in this general ballpark. 
the 'naïve picture'. It thus makes sense for methodological examination in philosophy to begin with examining the idea that philosophers use intuitions and their use of intuitions has something to do with evidence/justification/support.

Note that this naïve picture does little to solve the epistemological puzzles about philosophical enquiry. It simply gives them a name and provides focus for methodological discussion. The role, nature and epistemic status of these 'intuitions' are hardly cleared up simply by naming them. For instance, I don't take the naïve understanding - as I understand it - to come down definitively either way on the question of whether the justification which intuitions ultimately do or do not provide would be a priori or a posteriori. ${ }^{2}$

\subsection{Losing sight of the reasons to focus on intuitions}

My misgivings about the current state of methodological debate primarily concern the way it has focused on whether intuitions do or should play an evidential role in arguments in philosophy. I think this focus has lead to methodologists losing sight of why it makes sense to methodologically examine the role of intuitions in philosophy. In order to articulate my misgivings, I want to focus on a recent trend in philosophical methodology. A great number of philosophers have recently come out as being rather down on the idea that intuitions play an important evidential role in philosophy. I don't claim this is some kind of coherent movement-the relevant philosophers don't agree and have very different general outlooks-however, at a certain level of abstraction the trend is there.

1. Williamson (2007) thinks philosophers make a mistake if they think their evidence consists largely in their intuitions.

2. Ichikawa (2014) thinks philosophers' appeals to intuitions are largely not about adducing evidence but rather dialectical manoeuvring.

3. Cappelen (2012) thinks philosophers don't actually make the mistake of relying on intuitions as evidence.

4. Deutsch (2010) thinks what matters is not whether a counterexample is intuitive, but whether it is a counterexample, and consequently that focusing on intuitions is a mistake.

\footnotetext{
${ }^{2}$ Some even think the terminology of 'intuitions' is actively unhelpful. One of Cappelen (2012)'s claims is that talking in terms of intuitions has been a great source of distraction in methodology. As we will see, I agree that methodologists have been distracted, but I don't think abandoning talk of intuitions will get rid of the problem.
} 
5. Kornblith (2007) thinks intuitions serve as evidence as to the nature of our concepts, but that since philosophers shouldn't be quite so interested in concepts, we should stop most of our intuition-mongering.

6. Various folks think we need to restrict our use of intuitions as evidence on the basis of empirical evidence that intuitions are unreliable (e.g., Swain, Alexander, and Weinberg 2008; Weinberg, Nichols, and Stich 2001). ${ }^{3}$

7. And, various people, starting with Cummins (1998), worry that whether or not intuitions can be calibrated they are of no use to us in philosophy.

Given the naïve picture of place of intuitions in philosophy, this current fashion in methodology might seem somewhat strange. One might wonder whether methodologists can possibly hold the views that their slogans advertise. They wield slogans like 'Philosophers don't use intuitions!' and 'Philosophers shouldn't use intuitions!' But can it really be that the naive picture of the role of intuitions in philosophy is so very wrong/problematic? Is that really what these philosophers think? Philosophy, if it is possible, must have some epistemic grounding even if it is puzzling. The naïve view may be vague and imprecise-we surely want a much better understanding of these 'intuitions' and their role in philosophy-but can these methodologists really have such a problem with it? The answer might come as a surprise to an outsider to the debate. The answer is no. Once one looks behind the slogans, it is clear that none of these methodologists really have a big problem with the naïve picture at all.

Let's look a little closer at each in turn.

1. It turns out that Williamson's beef is with philosophers who refuse to treat the claims they judge to be true as evidence, and instead treat their evidence as consisting only (or largely) of psychological claims such as it is intuitive that $p$. We can agree with him about this: it would be problematic if philosophers thought their evidence was purely psychological; this would concede ever-so much unnecessary ground to the skeptic. But it is not as if Williamson wants to deny that our ordinary capacities for thinking about things in some way supply our evidence in philosophy.

2. Ichikawa's position is very similar to Williamson's (with some interesting additional claims about how use of the word 'intuition' serves a dialectical purpose: to avoid begging the question).

3. It turns out Cappelen's ire concerns metaphilosophers' obsession with the idea that philosophers rely on intuitions as construed in certain very particular ways as evidence in a distinctive way. His conclusion that philosophers don't rely on

\footnotetext{
${ }^{3}$ I have contributed to this literature (Andow forthcoming).
} 
evidence is made on the basis of an empirical project examining philosophical texts. When Cappelen finds no evidence that philosophers use intuitions, it turns out that what he was looking for was something very particular: use of judgments which (i) have a characteristic phenomenology, (ii) are treated as having no need of justification, (iii) which philosophers remain inclined to endorse even if their arguments for the contents of those judgments are revealed to be bad arguments, (iv) whose use in philosophy is distinctive or characteristic to philosophy, and/or (v) are necessary claims without the other features (i-iv). We can concede Cappelen this point easily, it is not as if Cappelen denies that 'philosophers rely on intuitions' is true where (a) we construe 'intuitions' in a rather less rich way (perhaps using what Weinberg and Alexander (2014) dub a 'thin' characterization, i.e., identifying them merely as 'instances of some fairly generic and epistemologically uncontroversial category of mental states or episodes', see Andow 2016 for an independent argument for such an approach) and (b) 'philosophers rely on intuitions' is not understood to mean something which precludes that philosophers are willing to provide extra reasons to believe the intuitive claims.

4. Deutsch doesn't really seem to deny that our identification of cases as counterexamples must ultimately rely upon some sort of intuition. He just thinks that what we are looking for is genuine counterexamples and that the appropriate response to someone who doesn't share your intuition that something is a counterexample is, in the first instance, to give them reasons to accept that it is a counterexample. But, who would deny that?

5. It turns out Kornblith thinks that intuitions are an essential first step in enquiry into philosophically interesting phenomena, but that philosophers often take intuition-based enquiry too far (e.g., they try to give an account which preserves as many intuitions as possible). Again, this seems perfectly reasonable, and not so much at odds with the naïve picture. ${ }^{4}$

6. Even folks who say we should restrict our use of intuitions on the basis of empirical evidence turn out to be making rather less radical recommendations than those they are sometimes painted as making. Certain types of intuition are variable in certain ways, they say, and you probably want to be careful with those intuitions.

\footnotetext{
${ }^{4}$ Moreover, it seems that Kornblith's only target is pretheoretic intuitions about cases which are immediately obvious. He says, for example, "The standard approach in philosophy of beginning with individual cases is no different in kind than selecting clear-cut cases of a natural kind for further investigation... [This,] however, should not be seen as simply a matter of consulting our intuitions about cases. The features which members of a kind share... may be ones which are not immediately apparent." (Kornblith 2007, 47)
} 
7. Finally, it turns out the substance of Cummins' position is that intuitions can't play the role in reflective equilibrium in philosophy that observations play in science. ${ }^{5}$ Cummins' reasoning is that intuitions either stem from explicit or tacit theories. He thinks that explicit theories, if they ground intuitions, supplant any epistemic contribution intuitions might make, and tacit theories fare no better since they are going to be biased (if acquired) or likely to be pretty inaccurate (if innate). However, this argument is too fast, the conclusion that we shouldn't use intuitions or that intuitions are useless would be premature. No one thinks enquirers should eschew all sources which are less than perfect. A more sensible response to Cummins' considerations is that we should be more careful with intuitions.

\subsection{The need for reorientation}

In other words, the slogan versions of these views oversell the criticisms these folks truly offer. None of these methodologists have any robust criticism to offer that targets the naïve picture of intuitions' role in philosophy. Insofar as these criticisms damage the view that intuitions play an evidential role in philosophy, it is only a rather specific version of that view which is damaged: the view that says the way that intuitions play an evidential role in philosophy is by philosophers using intuitions as premises (or to support premises) in arguments. However, all these arguments are widely taken to do rather more general damage to the view that intuitions do/should play an evidential role in philosophy-that's the sense in which I think the way methodological discussion proceeds often fails to engage with the naïve picture.

Now I should note that all the arguments and positions surveyed above do make important contributions to our understanding of philosophical methods. What they make clear is that it is incredibly difficult to elaborate on the naïve picture without painting a picture which is obviously problematic. For example, it is problematic to think that intuitions comprise the bulk of philosophers' evidence and that we don't allow other considerations to influence our theorizing. Likewise, it is problematic to think that what plays the justificatory role when philosophers appeal to cases is an intuition about a case rather than an (intuitive) fact about the case. To think that once we appeal to an intuition, our case rests on it and we won't be willing to adduce further considerations is also problematic. To think that intuitions are somehow special and their use is somehow distinctively philosophical, is perhaps the most problematic of them all.

However, to take these contributions to cast doubt on the general idea that intuitions do or should play an evidential role in philosophy is to miss the point of why

\footnotetext{
${ }^{5}$ At least, that's what I take his arguments to establish (if anything). I don't deny that his explicit statements of his views are somewhat stronger.
} 
it makes sense to methodologically examine the role of intuitions in philosophy in the first place. Those are my misgivings. I think that fixating on whether intuitions are or should be used as evidence by philosophers in their arguments leads methodology astray. Perhaps more precisely, I think the problem is the tendency to equate the basic naïve view that a good story about philosophical methodology and/or the epistemology of philosophy would do well to say something about intuitions and this rather more specific view. What to do? The debate needs reorienting. We need a better framework for thinking about the role of intuitions in philosophyone which allows methodologists to better engage with the naïve picture. Of course, until I provide a better way to elaborate upon the naïve picture, I might be accused of merely stalling a bad debate rather than having advanced a good one. So, here goes ...

\section{The abductive model}

Here's the basic abductive model. The overall project of giving a theory of some phenomenon $\phi$ is at heart an abductive exercise. We want a theory which best explains the evidence we have about $\phi$. We have a lot of evidence. In philosophy, and probably elsewhere too, much of that evidence either comes from intuition (we come to believe the relevant propositions via intuition) or is psychological (it consists in claims about what we find intuitive, about how our intuitive processes work, etc.).

There are two things I need to elaborate upon here. (1) What I mean by saying philosophers have a lot of evidence including intuitions. (2) What I mean by saying philosophy is 'at heart' an abductive exercise. But, first, let me remind the reader about the nature of the suggestion I aim to provide. The point of this paper is to suggest a reorientation of philosophical methodology. The suggested reorientation is to (i) stop thinking about the role of intuitions as evidence in philosophy by starting with questions like 'What's playing the role of evidence in philosophers' arguments?' and 'When philosophers argue, what do they explicitly appeal to as evidence?' and (ii) to start instead with some sort of minimal abductive picture. ${ }^{6}$

The abductive model really is supposed to be minimal. My aim is not to articulate a fully worked out account of philosophical methodology or epistemology. My aim is to suggest that those who are interested in articulating a fully worked out account of philosophical methodology or epistemology start by thinking about philosophy as being at heart an abductive enterprise. I don't claim to have already worked out

\footnotetext{
${ }^{6}$ This is not a principled maneuver in that I don't think there is an in principle reason why approaching the issue by asking such questions is problematic. Rather it is a pragmatic one. By focusing on such questions, the debate seems to have gone awry. If there is an alternative, it might be worth a shot.
} 
exactly how philosophy works or should work. If I had, then I wouldn't be suggesting a reorientation of methodological discussion, and would be going with a rather stronger headline. ${ }^{7}$ So, let me be clear up front that there are various things which one might want from 'an abductive model of (intuitions' role in) philosophical enquiry' which my abductive model will not give you. I'll address some of these in a moment when I articulate what my abductive model does say and what it does not say when it says that philosophical enquiry is 'abductive at heart'.

\subsection{Philosophers have lots of evidence}

Philosophers have lots of types of evidence. A basic distinction we might make is that between first and second order evidence. ${ }^{8}$

Suppose that one is engaged in, for example, theory of knowledge. Philosophers interested in giving an account of knowledge can and do draw on all of the following first order evidence: ordinary judgments about cases supply/put us in contact with certain facts; linguistic data of various kinds put us in contact with others; cross-cultural linguistic or psychological data give us others; reflecting on the social function the concept knowledge has is also important; thinking about the varying epistemic situation of different demographic groups, e.g., about epistemic injustice, is an important source of insight; so too is information about our belief forming processes/aids, e.g., about perception and science, and information about testimonial practices and how they develop. So, more generally speaking, we might say that philosophers' first order evidence concerns facts about cases, situations, propositions about the world, maths/logic, etc. We come to believe such facts in a variety of ways. Some we come to believe using our intuitions, while others come from scientific findings, our experience, phenomenology, etc.

Second order evidence then concerns facts about our first order evidence. Philosophers' second order evidence includes facts about what 'we', people generally, or perhaps some particular linguistic community find intuitive. Second order evidence also includes many other facts: about what our intuitions entail; about where our intuitions come from; about how we come to our judgments about cases; about how strong our intuitions are; about how reliable our intuitions are about the particular subject matter in hand; about the stability of our intuitions; and so on for other sources of evidence like the instruments of science, or linguistic data. Second order evidence about knowledge, for example, might include facts about how we identify the social function of the concept of knowledge. Second order evidence

\footnotetext{
${ }^{7}$ One way to put this might be to say that the aims of this paper might be said to be metamethological rather than straightforwardly methodological (a similar distinction is employed by Andow 2016).

${ }^{8}$ Don't take the distinction between first and second order evidence too seriously. There are not two distinct kinds of evidence. We have evidence. Some of it concerns other evidence. The distinction is just trying mark that fact.
} 
also includes facts about arguments for/against various positions in the vicinity, and reasons too. For example, among the evidence relevant to giving a theory of the content of moral claims, is the fact that the Frege-Geach problem is a hurdle faced by non-cognitivists.

\subsection{Philosophy is abductive at heart}

This is not a methodological claim in the sense of a claim about what philosophers do day-to-day, about what kinds of move they purposefully employ, or about what types of arguments or inferences philosophers employ. Rather, the claim that philosophical enquiry is abductive at heart is supposed to be a deep claim about what kind of enterprise doing philosophy is. The thought is that by starting with a broadly abductive picture of what kind of enterprise philosophy is, we can then start to work out the details, e.g., we can start to ask questions about how intuitions play an evidential role in philosophy, in a way that doesn't run the risk of failing to engage with the reasons why it makes sense to methodologically examine the role of intuitions in philosophy. There isn't really anything more to the abductive model which I think we should start with, beyond what I have already stated. However, I do want to take some time to distance myself from various claims which it might be supposed an advocate of an abductive model of philosophical enquiry might endorse.

To say philosophical enquiry is abductive at heart is not to say that abductive inferences should or do play a big role in day-to-day philosophizing. Philosophy might be essentially an abductive enterprise even if it were the case that no philosopher had ever utilized any form of abductive inference. (Doubtless, philosophers often do make abductive inferences but that claim is not what characterizes the abductive model of philosophical enquiry.)

To say that intuitions are part of the evidence which philosophical enquiry attempts to explain is not to say that explicit appeals to intuitions as evidence should or do play a big role in actual philosophizing. ' The whole point of suggesting the abductive model as an alternative is to get away from the focus that methodology has had on questions about whether philosophers use intuitions as evidence in suchand-such an argument. To say that philosophical enquiry is abductive at heart is not to say that there is anything distinctively philosophical about enquiry which is abductive at heart. (Indeed it sounds pretty plausible to me to say that all enquiry is abductive at heart and that philosophy is the most general form of enquiry there is.

\footnotetext{
${ }^{9} \mathrm{I}$ 'm relying on a distinction between (i) facts which constitute our evidence and (ii) facts we actually appeal to. In any domain, it would be absurd to think nothing we don't explicitly appeal to constitutes part of our evidence. One adduces pertinent facts, salient facts, facts one expects one's interlocutors to recognize. One's evidence includes lots of other things too. We shouldn't be tempted to think a class of facts are not actually part of philosophers' evidence, simply because philosophers tend not to appeal to such facts.
} 
But I don't argue for either of those claims here.) Likewise, to say that philosophical enquiry is aimed towards explaining the evidence isn't to suggest that the philosopher's search is one for any particular type of explanation. There are many types of explanation. There are causal explanations. There are deductive-nomological explanations. There may even be some distinctively philosophical variety of explanation. My sense is that different philosophical debates are likely after different types of explanation. Certain debates in philosophy of biology might be after causal explanations. Certain debates about grounding relations might be after a distinctively philosophical explanation. But the claim made by the abductive model is simply that philosophy is at heart an abductive exercise and not that it is after any particular variety of explanation.

The model I suggest we start with when thinking about the role of intuitions in philosophy is simply that what philosophy as an enterprise is ultimately after is the best explanation of all the available evidence which includes intuitions and evidence about intuitions. Now we can start asking more procedural, methodological questions about how philosophy is done and about good, bad and better ways of going about philosophizing.

\subsection{How does the abductive model help?}

This abductive model can provide us with a better starting point from which to begin our exploration of the role of intuitions in our evidence for positions.

Let's take the example of the role of intuitions in my evidence against the JTB account of knowledge. I am fairly confident that the JTB account of knowledge is not the best account. Part of my evidence involves Gettier cases in which folks have JTB without knowing. If challenged, I can adduce (facts about) such cases as evidence. However, the evidence I adduce is far from being my entire evidence. I have a great amount and variety of evidence behind my position. I have thought about what would follow from treating gettierized protagonists as being unjustified. I have paid close attention to how robust my commitment to Gettier cases being cases of non-knowledge is. I have tried and failed to put myself in the position of folks who are willing to attribute knowledge. I also got really worried when it looked like there might be significant cultural variation in intuitions about Gettier cases. Part of my current evidence consists in there being no strong and concrete reason to doubt my ability to discern knowledge from non-knowledge. So I have lots of evidence, not just the bits of evidence which I'd be likely to evince in defence of my position.

How does the minimal abductive model deal with this example? First, it is completely uncontroversial that intuitions and/or evidence about intuitions-in the somewhat vague rather imprecise notion which collects together various things like pretheoretic beliefs and judgments we are disposed to have concerning actual and 
hypothetical cases, and other stuff too-are part of my evidence here. So the abductive model doesn't run the risk of completely failing to engage with the naïve picture.

Second, the abductive model now provides us with a framework to ask questions about what is going on when philosophers advance arguments. In this case, we might ask exactly what is going when people use arguments such as Gettier's against the JTB account of knowledge. We can ask: What role are arguments playing vis-Ãă-vis philosophers' evidence? And, here's an answer worth considering: The role of arguments is to draw attention to particular bits of evidence in the hope of persuading the unpersuaded. What evidence might that be? At this point in the enquiry, we can hand the baton back to the debates which have been raging among philosophical methodologists in recent years on this very topic. However, importantly, the question 'Do (or should) intuitions play a role in this argument?' will not be understood to be equivalent to 'Is (or should) evidence from or relating to intuitions (be) any important part of our evidence against the JTB account?' (in particular, a negative answer to the first question won't be taken to entail a negative answer to the second).

Third, the abductive model allows us to incorporate any genuine insights from the extant methodological literature which I surveyed at the beginning. For example, the abductive model allows one to say that it is problematic to think that what plays the evidential role when philosophers appeal to cases is an intuition about a case rather than an (intuitive) fact about the case. But, on the other hand, it also allows one to recognize that this is not all there is to be said (as the relevant body of evidence is far more extensive than the evidence evinced and this may well include intuitions or facts about intuitions rather than just intuitive facts). For another example, the abductive model allows recognition that intuitions do not comprise the bulk of philosophers' evidence and that we allow other considerations to influence our theorizing.

Fourth, in the end, there doesn't seem to be any obvious reason why any of the methodologists whose views we surveyed at the beginning should object to this general abductive picture. In particular, they all seem amenable to the idea that evidence about evidence, in particular evidence about intuitions, is philosophically relevant in some more holistic way (even if the slogan versions of their views would suggest otherwise).${ }^{10}$ Here are a couple of examples:

1. Williamson (2013) claims,

\footnotetext{
${ }^{10}$ Perhaps the only exception is Cappelen (2012). He seems to think that information about our judgement-forming processes is utterly irrelevant in philosophy. His book has a chapter titled 'A Big Mistake: Experimental Philosophy' and the mistake he thinks experimental philosophers make is to think such information could be relevant. However, it seems Cappelen overlooks, rather than argues against, the types of potential import discussed by these other authors.
} 
If the experiments [looking at intuitions] have been properly designed and conducted, they still reveal unexpected and intriguing patterns in ordinary human judgments about philosophically central matters... simply ignoring them would be imprudent and incurious. Even if they turn out to result from various kinds of bias, a philosophical training is unlikely to render one entirely immune to such bias. Understanding a source of bias is a step towards correcting for it. (p.472)

2. Ichikawa (2014) largely agrees with Alexander and Weinberg (2007) when they say that a certain kind of import such evidence might have (the idea philosophers should be worried about their use of intuitions),

does not need to turn on a (potentially mistaken) psychologization of philosophers' evidence .... In terms that Williamson should be happy with, the challenge reveals that at the present time philosophers may just not know what their evidence really is. And the true extent of their evidence is not, we think, something that they will be able to learn from their armchairs. (p.72)

The non-armchair resources they have in mind are those which gather empirical evidence about our intuitions, ordinary judgement forming processes, and so on.

3. Ichikawa and Jarvis (2013) claim,

What [evidence of intuitions' unreliability] indubitably show is that many, perhaps all, judgments that are putatively a priori knowledge are susceptible to a posteriori defeaters. One can always acquire empirical reason to believe that one's a priori faculties are functioning poorly and ought not to be trusted. (p.188)

4. Deutsch (2010) expresses interest in finding out more about intuitions, but thinks the project won't be a philosophical one, saying,

What explains cross-cultural variability in philosophical intuitions, even if it is a mistake to think such variability poses a severe problem for traditional philosophizing? That is a good question-for a social scientist. (p.459)

But that shouldn't concern us, lots of our evidence in philosophy is gathered by nonphilosophers (e.g., physicists, psychologists, anthropologists, and so on). 


\subsection{Hasn't $\mathrm{X}$ already made this suggestion?}

I don't claim to be the first person to have said that abduction and philosophical methods or epistemology might have something to do with each other. Various other authors have recently suggested that philosophy may involve abduction to a rather larger extent than has traditionally been assumed. My suggestion, however, is rather more than that and none of these recent authors have suggested the approach to methodology which I have advocated here. Nonetheless, I do take the presence of this trend towards thinking about the relation between philosophy, methodology and abduction to be a source of optimism that the world of philosophical methodology may be open to my suggestion. So, before I finish, let me quickly run through some of these hints of abductive flavors in other authors by means of (a) noting how my suggestion differs and (b) noting that the time seems to be ripe for considering a more abductive picture of philosophical enquiry.

1. Perhaps the closest to the abductive picture I have painted is apparent in Love (2013). Love brings out an abductive theme in two recent books Alexander (2012) and Cappelen (2012). These authors pictures of philosophical methods are other wise diametrically opposed, but Love makes clear that they share a common assumption that philosophy shares with science the method of 'hypothesis testing and theory confirmation', according to which, 'A mature... theory is one that better explains the array of data available than its competitors' (Love 2013, sec. 3). However, Love himself wishes to distance himself from this picture of enquiry in either science or philosophy. Cappelen thinks evidence about intuitions is simply irrelevant in philosophy (as discussed earlier). And Alexander, although coming close to diagnosing a rather similar issue in Williamson (2007) to that I discuss above (Alexander 2012, 102-7), leans instead on a 'dialectical' model of the role intuitions play in arguments.

2. Ichikawa and Jarvis (2013) also endorse a similar idea that philosophy shares an abductive flavour with other types of enquiry: saying that it

- $\quad$...draws on the same cognitive resources that subjects marshal in ordinary cases of so-called "abductive" inquiry. Even when instancing pure rational thinking, philosophical inquiry sometimes has the flavor of abduction whereby global theoretical considerations throughout one's 'web of belief' are brought to bear on answering a philosophical question. (Ichikawa \& Jarvis 2013, p.4)

- Later in the book, it is suggested that this makes philosophical thinking structurally analogous to 'scientific thinking' (Ichikawa and Jarvis 2013, p.223). 
However, their overall model of enquiry doesn't seem to be one which is abductive at heart, and their model of the role of intuitions in philosophy is careful not to place them in an evidential role.

1. Deutsch (2015) gives time to the idea that the arguments philosophers actually give-such as Gettier's-might be abductive in character at least in part. I make no such claim.

2. Cummins (1998) suggests that instead of placing such great emphasis on intuitions about cases we should do like scientists do and give a greater emphasis on appeals to explanatory virtue. However, his is a procedural suggestion and a supposedly ameliorative one, so he is doing something rather different.

3. Various folks have also looked at the role of explanation in philosophy from rather different angles again, e.g., whether certain philosophical positions and arguments are engaged in explaining certain facts (for discussion, see Daly 2010 chp.5), or whether metaphysicians' talk of 'fundamentality' is best understood in terms of explanation (see Jenkins 2013). Again, this isn't what I'm doing.

Although these projects are obviously not completely unrelated to my current project, none of them is suggesting that it would be beneficial to approach questions about intuitions, evidence and philosophy with a broadly abductive picture of philosophical enquiry. Indeed, none makes a metamethodological point about how methodologists should proceed. ${ }^{11}$

\section{Conclusion}

The ambitions of this paper are pretty modest. I do not intend to defend a fully detailed model of how philosophy works either in terms of its methods or its epistemology. The aim is to provide a framework for methodological discussion, especially about the role of intuitions in philosophy, which helps to deal with certain misgivings that I have about the way discussion in philosophical methodology typically proceeds.

The least modest central claims of the paper can be summarized as follows.

1. There is something wrong with the way that methodological discussion often proceeds. For instance, I really think it is problematic to approach the examination of the role of intuitions in philosophy in such a way that one might

\footnotetext{
${ }^{11}$ One important sign that some of these folks are not making anything like the same suggestion I make here is that they also appear in the list of examples I gave near the beginning of this paper.
} 
end up defending the idea that philosophers don't use intuitions but which in no way impugns the naïve picture according to which intuitions do play an important role in philosophy and which provided the motivation for talking about philosophical methodology in terms of intuitions in the first place.

2. Second, one way to reorient philosophical methodology, such that this sort of regrettable situation does not occur, is for the methodologist to start out with the sort of minimal abductive model of philosophical enquiry which I suggest. The starting picture should be a model according to which evidence from intuitions is part of philosophers' evidence and the aim of enquiry is to end up with a theory which best explains all the evidence (where what is meant by 'intuitions' is a somewhat vague and imprecise collecting together various things like pretheoretic beliefs and judgments we are disposed to have concerning actual and hypothetical cases, and other stuff too). This starting point is supposed to be an alternative to the starting point which many implicitly seem to adopt: that any interesting question about the role of intuitions in philosophy concerns whether philosophers use intuitions as evidence when they provide certain kinds of arguments.

3. Third, it would be a good idea for methodologists to use something like the outlook provided by the abductive model rather more often.

But, I'll finish by emphasizing once again that there is no huge revolution suggested here. Although I think certain ways of approaching philosophical methodology have been problematic, it is not as if the results of approaching methodology in those ways need to be wiped from the slate. Indeed it is a virtue of the abductive model that having adopted such an outlook one can nonetheless be well placed to incorporate the various insights provided by other methodologists-including those who have criticized the idea that philosophers use intuitions or criticized intuitionuse-albeit not in their sloganized forms. For example, one is well placed to accept that psychological facts are rarely actually adduced as evidence by philosophers (and perhaps that it would be problematic for them to be used in this way). For another example, one is well placed to accept that it is healthy to retain some skepticism about (and caution when) relying upon evidence from or about intuitions. The lens provided by the abductive model will help one see any unhelpful slogans for what they are but needn't impede incorporating any insights which lie behind those slogans.

Mailing address: Dr James Andow, Dept. of Philosophy, University of Reading, Reading, UK, RG6 6AH

Email address: j.andow@reading.ac.uk (primary), jamesandow@gmail.com (secondary) 


\section{References}

Alexander, Joshua. 2012. Experimental Philosophy: An Introduction. Cambridge: Polity.

Alexander, Joshua, and Jonathan Weinberg. 2007. "Analytic Epistemology and Experimental Philosophy." Philosophy Compass 2, no.1: 56-80.

Andow, James. 2016. "Thin, Fine and with Sensitivity: A Metamethodology of Intuitions." Review of Philosophy and Psychology 7, no.1:105-125.

Andow, James. Forthcoming. "Reliable but not home free? What framing effects mean for moral intuitions." Philosophical Psychology.

Cappelen, Herman. 2012. Philosophy Without Intuitions. Oxford: Oxford University Press.

Cummins, Robert E. 1998. "Reflection on Reflective Equilibrium." In Rethinking Intuition, edited by Michael DePaul and William Ramsey, 113-28. Lanham, MD: Rowman \& Littlefield.

Daly, Christopher. 2010. An Introduction to Philosophical Methods. Peterborough, Ontario: Broadview Press.

Deutsch, Max. 2010. "Intuitions, Counter-Examples, and Experimental Philosophy." Review of Philosophy and Psychology 1, no.3: 447-60.

Deutsch, Max. 2015. The Myth of the Intuitive. Cambridge, MA: MIT Press.

Ichikawa, Jonathan. 2014. "Who Needs Intuitions?" In Intuitions, edited by Anthony Robert Booth and Darrell P. Rowbottom. Oxford: Oxford University Press.

Ichikawa, Jonathan Jenkins, and Benjamin Jarvis. 2013. The Rules of Thought. Oxford: Oxford University Press.

Jenkins, Carrie. 2013. "Explanation and Fundamentality." In Varieties of Dependence, edited by M. Hoeltje, B. Schnieder, and A. Steinberg. Munich: Philosophia Verlag.

Kornblith, H. 2007. "Naturalism and Intuitions.” Grazer Philosophische Studien 74, 
no.1:27-49.

Love, Alan C. 2013. "Experiments, Intuitions and Images of Philosophy and Science." Analysis 73, no.4: 785-97.

Swain, Stacey, Alexander Joshua, and Jonathan Weinberg. 2008. "The Instability of Philosophical Intuitions: Running Hot and Cold on Truetemp." Philosophy and Phenomenological Research 76, no.1: 138-55.

Weinberg, Jonathan, and Joshua Alexander. 2014. "The Challenge of Sticking with Intuitions Through Thick and Thin.” In Intuitions, edited by Anthony Robert Booth and Darrell P. Rowbottom. Oxford: Oxford University Press.

Weinberg, Jonathan, Shaun Nichols, and Stephen Stich. 2001. "Normativity and Epistemic Intuitions.” Philosophical Topics 29, no.1\&2: 429-60.

Williamson, Timothy. 2007. The Philosophy of Philosophy. Oxford: Blackwell.

Williamson, Timothy. 2013. "Review of Joshua Alexander, Experimental Philosophy: An Introduction." Philosophy 88, no.3:467-74. 